\title{
Complementary and alternative medicine for the treatment and diagnosis of asthma and allergic diseases
}

\author{
G. Passalacqua1 ${ }^{1}$ E. Compalati 1 , M. Schiappoli2, G. Senna²
}

\begin{abstract}
Complementary and alternative medicine for the treatment and diagnosis of asthma and allergic diseases. G. Passalacqua, E. Compalati, M. Schiappoli, G. Senna.

The use of Complementary/Alternative Medicines (CAM) is largely diffused and constantly increasing, especially in the field of allergic diseases and asthma. Homeopathy, acupuncture and phytotherapy are the most frequently utilised treatments, whereas complementary diagnostic techniques are mainly used in the field of food allergy-intolerance.

Looking at the literature, the majority of clinical trials with CAMS are of low methodological quality, thus difficult to interpret. There are very few studies performed in a rigorously controlled fashion, and those studies provid-
\end{abstract}

ed inconclusive results. In asthma, none of the CAM have thus far been proved more effective than placebo or equally effective as standard treatments. Some herbal products, containing active principles, have displayed some clinical effect, but the herbal remedies are usually not standardised and not quantified, thus carry the risk of toxic effects or interactions.

None of the alternative diagnostic techniques (electrodermal testing, kinesiology, leukocytotoxic test, iridology, hair analysis) have been proved able to distinguish between healthy and allergic subjects or to diagnose sensitizations. Therefore these tests must not be used, since they can lead to delayed or incorrect diagnosis and therapy. Monaldi Arch Chest Dis 2005; 63: 1, 47-54.

Keywords: Complementary/alternative medicines, asthma, allergic diseases, diagnosis, therapy.

1 Allergy \& Respiratory Diseases, University of Genoa

2 Allergy Unit, Verona General Hospital, Italy

Correspondence: Giovanni Passalacqua; Allergy \& Respiratory Diseases, Department of Internal Medicine; Padiglione Maragliano, L.go R. Benzi 10, 16132 Genoa Italy; e-mail: passalacqua@unige.it

\section{Introduction}

Medical approaches to diseases which differ from the conventional allopathic medicine are generally grouped, in western countries under the umbrella of alternative medicines. Indeed, some of these techniques represent the traditional medicine in several other countries and are part of the traditional medicine. Thus, the term complementary/alternative medicine $(C A M)$ should be preferred, since it does not imply an aprioristic negative judgment. Apart from those medical systems with a millenary history (Chinese, Japanese, Ayurvedic), there are numerous more recent CAM techniques (for instance homeopathy), where the number is contantly increasing. In particular, in the last decades, several holistic/behavioural approaches have been introduced. A list of the CAMs is reported in table 1 .

CAMs are widely and preferentially used to treat chronic diseases, such as headache, muscoloskeletal pain, irritable bowel, urticaria. Allergy and allergic diseases (including asthma and rhinitis) are therefore important fields for CAM, where homeopathy, acupuncture, herbal medicines and yoga are the most utilised techniques [1]. Also in the field of food allergy/intolerance, there is a wide and increasing use of diagnostic techniques that are often associated with behavioural/holistic or dietary treatments.

According to the most recent data, the percentage of subjects using or who have used CAMS in the general population ranges between 25 and $30 \%$, up to $50 \%$ in Australia [2,3] and USA [4]. Moreover, these percentages are constantly increasing, particularly in the last 20 years [5]. Recent studies have reported figures as high as $70 \%$ in Germany and France [6]. This widespread use is of course related to an impressive economic business $[7,8]$. Similar data has been reported also in the pediatric age, where at least $50 \%$ of children resulted to have been treated with CAMs [9]. In Italy, only two epidemiologic studies are available $[10,11]$, showing that among allergic patients about $30 \%$ are using CAMs. Interestingly, it emerged that about $80 \%$ of specialists were favorable to CAM and judged them of benefit for patients. The reasons for using CAMs usually reported by patients are: distrust in conventional medicine, the belief that CAMs are more natural and safe, and the need for a more strict relationship with the physician

As a matter of fact, allergists and pulmonologists have more and more often to afford the problem of patients who want to try CAMs in substitution of traditional medicine, or who have received 
Table 1. - Complementary/alternative medicines

\begin{tabular}{lll}
\hline Acupuncture & SYSTEMATIC MEDICINES & OTHER \\
\hline Homeopathy & Traditionale chinese medicine & Aromatherapy \\
\hline Herbal medicine & Japanese (Kampo) & Bach's flowers \\
\hline PHYSICAL TECHNIQUES & Indian (Ayurveda) & Chromotherapy \\
\hline Chiropractic & Sciamanic medicine & Enematherapy (hydro-colon) \\
\hline Massage & & Hypnosis \\
\hline Spinal manipulation & BEHAVIORAL & Hopi candles \\
\hline Breathing control & Dissociated diets & Iridology \\
\hline Yoga & Anthroposophy & Reflexology \\
\hline & Clinical ecology & Speleotherapy \\
\hline
\end{tabular}

a particular diagnosis for their allergy based on CAM diagnostic techniques. Thus, it is important that physicians are aware of the efficacy and contraindications of CAMs in order to provide patients with experimentally-supported information.

In this regard, due to the large diffusion of CAM, the high prevalence of allergic diseases, and the not negligible costs, that proof of efficacy are incontrovertible is definitely needed [12]. Only randomized controlled (possibly placebo-controlled) trials can be considered when judging the efficacy of a CAM treatment. Looking at the literature, the vast majority of the clinical trials with CAMs have a low qualitative level [13], thus making the results often difficult to interpret. On the other hand, it is claimed that "holistic" approaches cannot be standardised and submitted to rigorous study designs, because the standardisation itself introduces a confounding factor [14]. Finally, it has to be considered that some of the CAM techniques are self-applied (Yoga, relaxation techniques, biofeedback) and therefore cannot be blinded.

\section{Acupuncture}

Acupuncture is a cornerstone of the Traditional Chinese Medicine, and is widely used for chronic illness, including asthma. Acupuncture is intended to restore the balance of "vital flows" by inserting needles at exact points of the body surface, where the "meridians" of the flows lay. Specific points can be stimulated also by pressure or laser application. There are numerous studies of acupuncture in asthma, whereas few data is available for rhinitis and other respiratory diseases. An early systematic review of acupuncture in asthma was conducted by Kleijnen in 1991 [15]. In that review, 13 controlled studies were considered (6 double blind and 7 single blind): four of the double blind studies were negative and six of the single blind ones were positive. Based on the methodological quality of the studies, the Authors concluded, more than 10 years ago, that beneficial effects of acupuncture were more likely to be found in the low-quality studies. Things have not changed after 15 years: the most recent Cochrane reviews [16, 17], included 11 studies with 324 participants: trial reporting was poor, and quality was judged inadequate. Indeed, looking only at those studies performed with a rigorous methodology (i.e. randomised, controlled and blinded) [18-26], the effects of acupuncture are not different from the placebo treatments. Of note, only in two studies $[21,26]$ transient and mild benefits were demonstrated. Thus, the conclusion derived from meta analysis studied and clinical trials is that acupuncture is not effective to treat asthma.

Almost all studies of acupuncture in allergic rhinitis are not randomised, not controlled, or use weak methodologies [27-29]. There is only one randomised crossover trial [30] in seasonal rhinitis, with low methodological quality. In this study active acupuncture significantly reduced the symptom scores, without any change in the need for rescue medications. To date, based on the small amount of experimental data, acupuncture cannot be considered as a viable alternative to standard treatments for rhinitis.

Surprisingly, there is little data on the use of acupuncture in COPD, despite the fact that it is a typically chronic illness. One open study [31] demonstrated that both acupuncture and acupressure improve the quality of life of patients with COPD. In another recent randomised controlled study [32], it was shown that both real and sham acupuncture improved the dyspnea of COPD patients, without difference between active and control treatment. So far there is no experimentally supported indication to the use of acupuncture in COPD.

\section{Homeopathy}

Homeopathy is based on the belief that symptoms of a disease can be cured by the same substance that provokes them, if given at ultra-dilution. Homeopathic remedies are therefore chosen according to symptoms, not to disease, and prepared with a special manual technique called "potentiation". Homeopathy is a holistic approach to medicine that pays a special attention to the homeopath-patient relationship, and involves also behavioral and dietary approaches. Homeopathy has 
Table 2. - Randomized controlled studies with acupuncture in asthma

\begin{tabular}{|c|c|c|c|c|}
\hline AUTHOR & DESIGN & N. PATS & DUR AT & Main Results \\
\hline Biernacki & crossover & 23 & 1 day & $\begin{array}{l}\text { Improved QoL and } \downarrow \text { use of bronchodilators with both sham } \\
\text { and real intervention }\end{array}$ \\
\hline Christensen & Parallel group. & 18 & $5 \mathrm{wk}$ & $\downarrow$ symptoms and use of bronchodilators in the active group \\
\hline Gruber & Crossover & 44 & 1 day & No effect on isocapnic hyperventilation \\
\hline Joos & Parallel group & 36 & 4 wk & $\begin{array}{l}\text { No difference in pulmonary function and self-assessment. } \\
\downarrow \text { use of bronchodilators in both groups }\end{array}$ \\
\hline Malmstrom & Parallel group & 24 & $15 \mathrm{wk}$ & No effect on isocapnic hyperventilation with both treatments \\
\hline Medici & Parallel group & 64 & 16 wk & $\begin{array}{l}\text { No clinical difference among real, sham and placebo. Transient } \\
\downarrow \text { in PEF variability. } \downarrow \text { blood eosinophils in real VS sham }\end{array}$ \\
\hline Shapira & Crossover & 23 & $3 \mathrm{wk}$ & $\begin{array}{l}\text { No effect on PEF, } \mathrm{FEV}_{1} \text {, use of beta } 2 \text { agonists and } \\
\text { methacholine challenge }\end{array}$ \\
\hline Tandon & Crossover & 15 & $5 \mathrm{wk}$ & $\begin{array}{l}\text { No difference in PEF, } \mathrm{FEV}_{1} \text {, use of beta } 2 \text { agonists and asthma } \\
\text { score between groups }\end{array}$ \\
\hline Tashkin & Crossover & 25 & $4 \mathrm{wk}$ & $\begin{array}{l}\text { No difference in } \mathrm{FEV}_{1} \text {, use of beta } 2 \text { agonists and asthma score } \\
\text { between groups }\end{array}$ \\
\hline
\end{tabular}

been extensively studied in allergic diseases, and there are numerous well conducted and rigorous trials in both asthma and rhinitis. There are three randomized, placebo controlled, double blind studies in asthma [33-35]: these studies failed to demonstrate a mesurable clinical benefit on symptoms and functional parameters in adults [33, 34], and children [35].

There are also some studies in rhinitis [36-40]. The controlled study using a homeopathic dilution of Galphimia glauca for pollinosis, found no significant difference between active and placebo treatment [36]. Reilly et al, performed an early DBPC study in seasonal allergic rhinitis, evaluating a visual analog-scale and the intake of chlorpheniramine, and found a significant difference in favour of homeopathy for both parameters [37]. Another DBPC trial compared cromolyn and an intranasal homeopathic remedy (Huffa comp. Heel) and found no difference between the two treatments, both effective, in seasonal allergic rhinitis [38]. Taylor et al [59] performed another DBPC study in 50 patients with perennial allergic rhinitis. This study showed a significant improvement only in nasal flow in the active group, whereas the clinical improvement on a visual analog scale was the same in both active and placebo group. A homeopathic dilution of birch pollen provided only a marginal effect in seasonal allergic rhinitis [40], or even aggravated the symptoms during the pollen season [41]. In summary, there are three positive and three negative studies of homeopathy in rhinitis, therefore it cannot be recommended as an alternative to standard treatment. Finally, the recent reviews including all the trials (independent of the disease and the methods), conclude that some effect of homeopathy exists, but positive results are usually obtained in low-quality trials [17, 42-44].

No randomized and controlled study of homeopathy in chronic obstructive pulmonary disease, chronic Urticaria or food allergy is available in literature.

\section{Phytotherapy}

The traditional allopathic medicine is largely based on subtances derived from plants and herbs (e.g. theophillyne, salycilates, digitalis, morphine). Also the Chinese, Japanese and Ayurvedic medicines largely use herbs, often in fixed mixtures (e.g. ma huang and saiboku-to). The literature on herbal remedies is impressive, due to the large variety of herbs and their combinations used: tylophora indica, boswellia serrata, pychrorryza kurroa, koleus forskholii, gynko biloba, urtica and others. All these studies are generally of low quality (for a review see 45), but in many cases, a clinical effect can be measured in several diseases, including rhinitis and asthma. This is not surprising, because most of the herbs utilised contain pharmacologically active ingredients. Positive results were obtained in rhinitis and asthma with the mixtures of herbs used in the traditional Chinese medicine, which contain ephedrine and atropine. For instance, some studies with Tylophora indica [46, 47] have reported positive results in asthma. One double blind placebo controlled study performed in asthma subjects showed that the gum resin of 
Table 3. - Studies with homeopathy

\begin{tabular}{|c|c|c|c|c|c|}
\hline Author & DIS * & TREATM & CONTROL I & N PATS & FINDINGS \\
\hline Aabel & $\mathrm{R}$ & Birch 30c & Placebo & 66 & No effect on symptoms \\
\hline Aabel & $\mathrm{R}$ & Birch 30c & Placebo & 73 & No effect on symptoms \\
\hline Lewith & A & $\begin{array}{l}\text { Dust mite } \\
\text { homeopath }\end{array}$ & Placebo & 186 & $\begin{array}{l}\text { No difference between active and placebo in } \mathrm{FEV}_{1}, \mathrm{PEFR} \text {, } \\
\text { symptoms, use of b2 agonists and asthma score }\end{array}$ \\
\hline Reilly & A & $\begin{array}{l}\text { 30c dilution } \\
\text { of allergens }\end{array}$ & Placebo & $21-18$ & $\begin{array}{l}\text { No change in PEFR, pulmonary function and histamine challenge. } \\
\text { Significant improvement in the VAS }\end{array}$ \\
\hline Reilly & $\mathrm{R}$ & $\begin{array}{l}\text { 30c dilution } \\
\text { grass pollen }\end{array}$ & Placebo & 155 & $\downarrow$ symptom score, VAS and use of antihistamines \\
\hline Taylor & $\mathrm{R}$ & $\begin{array}{l}\text { 30c dilution } \\
\text { of allergens }\end{array}$ & Placebo & 50 & $\begin{array}{l}\text { TPNFR morning and evening. No difference betw groups } \\
\text { in VAS and symptom score }\end{array}$ \\
\hline Weiser & $\mathrm{R}$ & $\begin{array}{l}\text { Nasal } \\
\text { Luffa comp }\end{array}$ & Nasal cromone & 135 & Homeopathy $=$ nasal cromone, both effectiveon symptoms \\
\hline White & A & $\begin{array}{l}\text { Individ. } \\
\text { homeopathy } \\
\text { +drugs }\end{array}$ & $\begin{array}{l}\text { Placebo } \\
+ \text { drugs }\end{array}$ & 74 & $\begin{array}{l}\text { No difference between active and placebo in Asthma } \\
\text { QoLQ, PEFR, use of beta2 agonists, missing days }\end{array}$ \\
\hline Wiesenauer & $\mathrm{R}$ & $\begin{array}{c}\text { Galphimia } \\
\text { homeopathy } \\
\text { dilution }\end{array}$ & $\begin{array}{l}\text { Conventional } \\
\text { dilution/placebo }\end{array}$ & 104 & $\begin{array}{l}\text { No significant difference between active and placebo } \\
\text { treatments }\end{array}$ \\
\hline
\end{tabular}

Boswellia serrata (used in Ayurvedic remedies) was able to significantly improve symptoms and FEV1 after a 6-week course [48]. Two studies reported that saiboku-to (TJ96) improved asthma symptoms, exerted a steroid-sparing effect, reduced bronchial responsiveness and decreased sputum eosinophils in asthma patients [49, 50]. One controlled study in 8 asthmatics showed that an extract from Ginko biloba protected against bronchial specific challenge [51]. Despite the positive results reported, the quality of these studies was in general low and therefore not useful for giving recommendations. In fact the most recent meta analysis of herbal therapy in asthma produced negative results [52].

The same as for asthma happens with rhinitis, where some randomised controlled trials provided positive results. For instance, one study with a mixture of 18 Chinese herbs showed a significant efficacy of the treatment in seasonal rhinitis (symptoms and QoL) [53], and another the Chinese herb formulation biminne was statistically effective in perennial rhinitis [54]. One recent study using a combination of acupuncture and Chinese herbs found a significant effect on symptom scores and quality of life in seasonal allergic rhinitis [55]. On the other hand, a rigorous double blind randomized controlled trial showed that grapeseed extract was not more effective than placebo for ragweed induced rhinitis [56]. The most recent trial focused on butterbur (Petasites hybridus) extract in rhinitis. The first one [57] compared butterbur $400 \mathrm{mg}$ daily and cetirizine $10 \mathrm{mg}$ and found that both treatments were equally effective on symptom scores and QoL. The second study (58], in perennial rhinitis, confirmed that butterbur $400 \mathrm{mg}$ was equivalent to fexofenadine $120 \mathrm{mg}$ in controlling symptoms.

As far as COPD is concerned there is a controlled study utilizing the ginseng root $(100 \mathrm{mg}$ b.i.d.), where the herb, as add-on to standard therapy improved the tolerance to exercise [59].

Herbal remedies contain pharmacologically active substances that are responsible for the clinical effects. At the same time, the active ingredients may also induce undesirable side effects [60, 61]. Moreover, compared with proprietary marketing drugs, herbal remedies carry the risk of adulteration, incorrect collection of plants, wrong preparation and inappropriate/incorrect dosing [62].

\section{Behavioural, physical and other complementary treatments}

Physical techniques (e.g. breathing control, Yoga techniques and chiropractic/spinal manipulation) have been proposed in patients with chronic respiratory illness with the aim of improving the respiratory pattern. Indeed, most of the rigorous trials of chiropractic/spinal manipulation in asthma [63-65] failed to demonstrate a clinically relevant effect. In other studies, the effects were marginal [66-68]. The literature reviews conclude that breathing and yoga techniques can some effect on self-perceived well being, but they cannot be rec- 
ommended as an effective treatment for asthma $[69,70]$. Also behavioural techniques such as biofeedback and hypnosis have been sometimes applied in asthma, generally in low quality studies, but the overview of the literature concluded for no effect [71-72].

Also for behavioural/physical techniques, the literature concerning COPD is surprisingly poor. There is a randomised controlled open trial with relaxing techniques providing encouraging results concerning the perception of dyspnea in COPD patients [73]. There are also two studies with musictherapy $[74,75]$ and one with Yoga techniques [76) in COPD, but none of those studies were randomized or controlled. No controlled/randomized clinical trial in rhinitis or asthma has been performed with other alternative medicines (aromatherapy, chromotherapy, Bach's flowers, anthroposophy, clinical ecology). Therefore these techniques must not be recommended.

\section{Complementary/alternative diagnostic procedures}

There are numerous complementary/alternative diagnostic techniques available (table 4), often not based on experimental proof of concept [77]. These alternative techniques are largely used in the field of "food allergy/intolerance". This is probably due to the fact that many clinical diseases (e.g urticaria, migraine, irritable bowel, chronic fatigue syndrome, hyperkinetic syndrome) are often considered as "allergic", despite no formal demonstration is provided. In other words, "food allergy" is often considered as a simple pathogenic explanation of those symptoms which cannot be clearly classified. Indeed, the alternative techniques are also sometimes used to diagnose respiratory allergy. When evaluating the validity of such tests, a comparison with the "gold standard" (that is double blind placebo controlled food challenge for food allergy or skin prick test for respiratory allergy) should be performed.

Electrodermal tests are based on the hypothesis that skin electrical conductance changes when the subject comes into contact (even indirect) with noxious, allergenic or toxic substances. The skin conductance is measured through proper devices at specific acupoints, while the substances to test are introduced in the circuit. The earliest studies, not randomised and not blinded, reported a good cor- relation between electrodermal tests and specific IgE to inhalant allergens [78] and intradermal test [79] respectively. Indeed, the most recent studies, performed in double blind and randomized fashion, failed to demonstrate any correlation between the results of electrodermal testing and ascertained sensitizations [80, 81). In synthesis, the electrodermal test could not identify the allergic subjects and, in addition, displayed an unacceptable variability.

Leukocytotoxic tests are based on the hypothesis that peripheral leukocytes modify their shape or volume when they come into contact with noxious or allergenic substances [82]. The few studies available have shown an intrinsic and unacceptable variability of the method and a complete absence of correlation with clinical parameters [83-85].

Kinesiology. This method is based on the assumption that a reduction of the muscular strength of contraction occurs when the subject comes into contact with a noxious or allergenic substance. Usually, the subject has to keep in his/her hands or touch (but the direct contact is not mandatory) a vial containing the substance to test. The changes in muscle contraction are evaluated directly by the examiner or with a dynamometer. There are few well established studies evaluating the kinesiologic test $[86,87]$, invariantly failing to demonstrate the diagnostic value and reproducibility of the procedure.

Provocation/neutralization. This procedure is both a diagnostic and therapeutic tool. It is based on the belief that intradermal (or even sublingual) administration of noxious or toxic substances provokes "untoward effects" within 10-12 minutes. The test is considered positive irrespective of the type of effect observed or reported. Thus, the test is not standardized and is largely dependant on the personal interpretation. After a positive identification, the same substance that provoked the symptom(s) is given again to "neutralize" the adverse effect. Apart from numerous case reports and uncontrolled trials, there are few reliable studies on this test. Jewett and colleagues (88) in a double blind procedure found that active substance provoked symptoms in $16 \%$ and placebo in $24 \%$, without correlation with clinical history. Fox et al, (89) in another controlled trial in 132 patients concluded that "the results of provocation-neutralization testing, using symptoms alone as an indicator of neutralisation, should not be

Table 4. - Alternative diagnostic procedures

ELECTRODERMAL TESTS (Electroacupuncture): VEGA (TM), Dermatron (TM), DBE (TM)

BIOCHEMICAL TESTS: Leucocytotoxic test, ALCAT (TM), hair analysis

KINESIOLOGY: DRIA test and similar

IRIDOLOGY

PROVOCATION / NEUTRALIZATION: sublingual and intradermal 
used as a basis for clinical intervention". A nearfatal event was even reported in a subject suffering from mastocytosis [90].

Other tests. It has been claimed that it is possible to diagnose allergies/intolerances by analysing the hair content of metals and micronutrients. There is one controlled trial showing that the results of the test are completely random and that the variability among different operators and laboratories approximates $100 \%$ [91]. Iridology was proven to be completely unreliable and not supported by scientific evaluations as well [92].

In conclusion, none of the alternative/complementary techniques for diagnosing allergy/intolerance (expecially in the field of food allergy) is supported by a solid scientifical basis. They must not be used in clinical practice $[77,93,94]$.

\section{Conclusions}

Available scientific evidence does not support a role for CAMs in general in the treatment of asthma and other allergic diseases. More specifically, none of the proposed CAMs has been demonstrated capable of replacing the existing standard therapy. Moreover, the majority of the published studies have significant methodological flaws (e.g. small number of patients, lack of proper controls, inadequate blinding) that weaken the conclusions. Subjects treated are often not properly characterized in regard to asthma severity and use of conventional drugs. More rigorous studies are needed to confirm or to disprove the efficacy of CAMs. Some favourable results have been indeed obtained with phytotherapy, and this is not surprising since many herbs contain pharmacologically active principles. The main problem with herbal remedies is that they are usually non standardized, and represented by variable mixtures of substances. This fact may result in toxicity, drug interaction and adulteration. Therefore, further investigation into herbal treatments is important because it may possibly lead to the development of new useful medications.

Physicians often find CAM intimidating, because they are unaware of the clinical evidence and feel uncomfortable advising their patients on its efficacy. So there is definitely a need for improved education and knowledge among physicians, because the majority of patients are using or have used some form of CAMs. Physicians should inquire and discuss this issue in order to promote more successful treatment to their patients.

From a diagnostic point of view, to date there is no complementary or alternative diagnostic procedure which can be recommended as a meaningful element in the work-up of allergic diseases. This is especially true for food allergy for which properly performed oral double-blind placebo controlled food challenge still represents the gold standard diagnostic procedure. Ineffective diagnostic procedures may be costly for the consumer and result in delayed therapy or incorrect diagnosis.

\section{References}

1. Ziment I. Alternative therapies for asthma. Curr Opin Pulm Med 1997; 3: 61-71.

2. McLennan AH, Wilson DH, Taylor AW. Prevalence and cost of alternative medicine in Australia. Lancet 1996; 347: 569-73.

3. Ernst E. The role of complementary and alternative medicine. BMJ 2000; 321: 1133-35.

4. Blanc PD, Trupin L, Earnest G. et al. Alternative therapies among adults with a reported diagnosis of asthma or rhinosinusitis: data from a population-based survey. Chest 2001; 120: 1461-7.

5. Kessler RC, Davis RB, Foster DF et al. Long term trends in the use of complementary and alternative medical therapies in the USA. Ann Int Med 2001; 135: 262-268.

6. Fisher P, Ward A. Complementary medicine in Europe. Br Med J 1994; 309: 107-111.

7. Reilly D. Comments on complementary and alternative medicine in Europe. J Altern Complement Med 2001; 7 Suppl 1: S23-31.

8. Bielory L. Complementary and alternative medicine population based studies: a growing focus on allergy and asthma. Allergy 2002; 57: 655-58.

9. Shenfield G, Lim E, Allen H. Survey on the use of complementary medicines and therapies in children with asthma. J Pediatr Child Health 2002; 38; 252-257.

10. Senna GE, Passalacqua G, Crivellaro M et al Unconventional medicine: a risk of undertreatment of allergic patients. Allergy 1999; 54: 1117-1118.

11. Senna GE, Passalacqua G, Bonadonna P et al. Is alternative medicine acceptable in allergology? Allergy 2000; 55; 1200-1201.

12. Shekelle PG, Woolf SH, Eccles M, Grimshaw J. Clinical guidelines: developing guidelines. BMJ 1999; 318: 593-6.

13. Bloom BS, Retbi A, Dahan S, Jonsson E. Evaluation of randomized controlled trials on complementary and alternative medicine. In J Tchnol Assess Health Care 2000; 16; 13-21.

14. Mason S, Tovey P, Long AF. Evaluating complementary medicine: methodological challenges of randomised controlled trials. BMJ 2002; 325: 832-4.

15. Kleijnen J, ter Riet G, Knipshild P. Acupuncture and asthma. A review of controlled trials. Thorax 1991; 46: 799-802.

16. McCarney RW, Brinkhaus B, Lasserson TJ, Linde K. Acupuncture for chronic asthma. Cochrane Database Syst Rev 2004; (1): CD000008.

17. McCarney RW, Lasserson TJ, Linde K, Brinkhaus B. An overview of two Cochrane systematic reviews of complementary treatments for chronic asthma: acupuncture and homeopathy. Respir Med 2004; 98: 687-96.

18. Biernacki W, Peake MD. Acupuncture in treatment of stable asthma. Respir Med 1998; 92: 1143-1145.

19. Gruber W, Eber E, Malle-Schaed D et al. Laser acupuncture in children and adolescents with exercise induced asthma. Thorax 2002; 57: 322-325.

20. Malmstrom M, Ahlner J, Carlsson C, Schmekel B. No effect of chinese acupuncture on isocapnic hyperventilation with cold air in asthmatics, measured with impulse oscillometry. Acupunct Med 2002; 20: 66-73.

21. Medici TC, Grebski E, Wu J, Hinz G, Wuthrich B. Acupuncture and bronchial asthma: a long-term randomized study of the effects of real versus sham acupuncture compared to controls in patients with bronchial asthma. J Altern Complement Med 2002; 8: 737-50.

22. Shapira MY, Berkman N, BenDavid G et al. Short term acupuncture is of no benefit in patients with moderate persistent asthma. Chest 2002; 121: 1396-1400. 
23. Tashkin DP, Kroening RJ, Bresler DE, Simmons M, Coulson AH, Kerschnar H. A controlled trial of real and simulated acupuncture in the management of chronic asthma. J Allergy Clin Immunol 1985; 76: 855-64.

24. Tandon MK, Soh PF, Wood AT. Acupuncture for bronchial asthma? A double blind crossover study. Med J Aust 1991; 154: 409-412.

25. Joos S, Schott C, Zou H, Daniel V, Martin E. Immunomodulatory effects of acupuncture in the treatment of allergic asthma: a randomized controlled study. J Altern Complement Med 2000; 6: 519-25.

26. Christensen PA, Laursen LC, Taudorf E, Sorensen SC, Weeke B. Acupuncture and bronchial asthma. Allergy 1984; 39: 379-85.

27. Lai X. Observation on the curative effect of acupuncture on type I allergic diseases. J Tradit Chin Med 1993; 13: 243-8.

28. Yu S, Cao Z. Acupuncture treatment of chronic rhinitis in 75 cases. $J$ Tradit Chin Med 1993; 13: 103-5.

29. Xia Z, Xu L. Acupuncture at agger nasi for treatment of allergic rhinitis. J Tradit Chin Med 1997; 17: 278-9.

30. Xue CC, English R, Zhang JJ, Da Costa C, Li CG Effect of acupuncture in the treatment of seasonal allergic rhinitis: a randomized controlled clinical trial. Am J Chin Med 2002; 30: 1-11.

31. Maa SH, Sun MF, Hsu KH, Hung TJ, Chen HC, Yu CT, Wang CH, Lin HC. Effect of acupuncture or acupressure on quality of life of patients with chronic obstructive asthma: a pilot study. J Altern Complement Med 2003; 9: 659-70.

32. Lewith GT, Prescott P, Davis CL. Can a standardized acupuncture technique palliate disabling breathlessness: a single-blind, placebo-controlled crossover study. Chest 2004; 125: 1783-90.

33. Reilly DT, Taylor MA, Beattie NGM et al. Is evidence homeopthy reproducible. Lancet 1994; 344: 16011604.

34. Lewith GT, Watkins AD, Shaw H, Dolan G, Holgate ST Use of ultramolecular potencies of allergen to treat asthmatic people allergic to house dust mite: double blind randomised controlled trial. BMJ 2002; 324: 1-5.

35. White P, Slade P, Hunt C, Hart A, Ernst E. Individualised homeopathy as an adjunct in the treatment of childhood asthma: a randomised placebo controlled trial. Thorax 2003 Apr; 58 (4): 317-321.

36. Wiesenauer M, Gaus W. Double-blind trial comparing the effectiveness of the homeopathic preparation Galphimia potentiation D6, Galphimia dilution 10(-6) and placebo on pollinosis. Arzneimittelforschung 1985; 35: 1745-7.

37. Reilly DT, Taylor MA, Mc Sharry C, Aitkison T. I homeopaty a placebo response? Controlled trial of homeopathic potency with pollen in hayfever as a model. Lancet 1986; 2: 881-886.

38. Weiser M, Gegenheimer LH, Klein P. A randomized equivalence trial comparing the efficacy and safety of Luffa comp. - Heel nasal spray with cromolyn sodium spray in the treatment of seasonal allergic rhinitis. Forsch Komplementarmed 1999; 6: 142-148.

39. Taylor MA, Reilly D, Lyewellyn-Jones RH, McSharry C, Aintchison T. Randomized controlled trial of homeopathy versus placebo in perennial allergic rhinitis with overview of four trial series. BMJ 2000; 321: 471-76.

40. Aaabel S, Laerum E, Dolvik S, Djupesland P. Is homeopathic isopathy effective? A double blind placebo controlled trial with the isopathic remedy betula C30 for patients with birch pollen Allergy. Br Homeopath $J$ 2000; 89: 159-60.

41. Aabel S. No beneficial effect of isopathic prophylactic treatment for birch pollen allergy during a low-pollen season: a double-blind, placebo-controlled clinical trial of homeopathic Betulla. 30c. Br Homeopath J 2000; 89: 169-73.
42. Linde $\mathrm{K}$, Clausius N, Ramirez $\mathrm{N}$ et al. Is the clinical effects of homeopathy placebo effects? A meta-analysis of placebo controlled trials. Lancet 1997; 350: 834-843.

43. Cucherat M, Haugh MC, Gooch M, Boissel JP. Evidence of clinical efficacy of homeopathy. A metaanalysis of clinical trials. HMRAG. Homeopathic Medicines Research Advisory Group. Eur J Clin Pharmacol 2000; 56: 27-33.

44. Jonas WB, Kaptchuck TJ, Linde K. A critical overview of homeopathy. Ann Intern Med 2003; 138: 393-399.

45. Huntley A, Ernst E. Herbal medicines for asthma. A systematic review. Thorax 2000; 55: 925-929.

46. Shipvuri DN, Singal SC, Prakash D. Treatment of asthma with an acoholic extract of tylophora indica: a double blind crossover study. Ann Allergy 1972; 30: 407412.

47. Mathew KK, Shipvuri DN, Treatment of asthma withh alkaloids of tylophora indica: a double blind study. Aspects Allergy Appl Immunol 1974; 7: 166-178.

48. Gupta I, Gupta V, Parihar A, Gupta S, Ludtke R, Safahi $\mathrm{H}$. Effects of boswellia serrata gum resin in patients with bronchial asthma: results of a double blind, placebo controlled 6-week clinical study. Eur J Med Res 1998; 17: 511-514.

49. Egashira Y, Hagano H. A multicenter clinical trial of TJ-96 on bronchial asthma. Ann N Y Acad Sci 1993; 685: 549-60.

50. Urata Y, Yoshida S, Irie Y, Tanigawa T, Amayashu H et al. Treatment of asthma patients with herbal medicine TJ-96: a randomized controlled trial. Respir Med 2002; 96: 469-474.

51. Guinot P, Brambilla C, Ducheir J et al. Effect of BN 52063, a specific PAF acether antagonist on bronchial provocation test to allergens in asthmatic patients. A preliminary study. Prostglandins 1987; 34: 723-31.

52. Huntley A, Ernst E. Herbal medicines for asthma. A systematic review. Thorax 2000; 55: 925-929.

53. Xue CC, Thien FC, Zhang JJ, Da Costa C, Li CG. Treatment for seasonal allergic rhinitis by Chinese herbal medicine: a randomized placebo controlled trial. Altern Ther Health Med 2003 Sep-Oct; 9(5): 80-7.

54. Hu G, Walls RS, Bass D, Ramon B, Grayson D, Jones M, Gebski V. The Chinese herbal formulation biminne in management of perennial allergic rhinitis: a randomized, double-blind, placebo-controlled, 12-week clinical trial. Ann Allergy Asthma Immunol 2002; 88: 478-87.

55. Brinkhaus B, Hummelsberger J, Kohnen R, Seufert J, Hempen $\mathrm{CH}$ et al. Acupuncture and chinese herbal medicine in the treatment of patients with seasonal allergic rhinitis: a randomized controlled clinical trial. $A l$ lergy 2004; 59: 953-960.

56. Bernstein DI, Bernstein CK, Deng C, Murphy KJ, Bernstein IL, Bernstein IA. Evaluation of the clinical efficacy and safety of grapeseed extract in the treatment of fall seasonal allergic rhinitis: a pilot study. Ann Allergy Asthma Immunol 2002; 88: 272-278.

57. Schapowal A. Randomized controlled trial of butterbur and cetirizine for treating seasonal allergic rhinitis. BMJ 2002; 324: 1-4.

58. Lee DK, Gray RD, Robb FM, Fujihara S, Lipworth BJ A placebo-controlled evaluation of butterbur and fexofenadine on objective and subjective outcomes in perennial allergic rhinitis. Clin Exp Allergy 2004; 34: 646-9.

59. Gross D, Shenkman Z, Bleiberg B et al. Ginseng improves pulmonary functions and exercise capacity in patients with COPD. Monaldi Arch Chest Dis 2002; 57: 242-46.

60. Barrett B, Kiefer D, Rabago D. Assessing the risks and benefits of herbal medicine: a review of the scientific evidence. Altern Ther Health Med 1999; 5: 40-49. 
61. Ernst E. Harmless herbs? A review of the recent literature. Am J Med 1998; 104: 170-8.

62. Ernst E. Adulteration of Chinese herbal medicines with syntetic drugs: a systematic review. J Int Med 2002; 252: 107-113.

63. Balon J, Aker PD, Crowther ER et al. A comparison of active and simulate chiropractic manipulation as adjunct treatment treatment for childhood asthma. $N$ Eng J Med 1998; 339: 1013-1020.

64. Cooper S, Oborne J, Newton S et al. Effect of two breathing exercises (Buteyko and pranayama) in asthma: a randomized controlled trial. Thorax 2003; 58: 674-79.

65. Vedantan PK, Kesavalu LN, Murthy KC et al. Clinical study of yoga techniques in university students with astma: a controlled study. Allergy Asthma Proc 1998; 19: 3-9.

66. Manocha R, Marks GB, Kenchington P, Peters D, Salome CM. Sahaja yoga in the management of moderate to severe asthma: a randomised controlled trial. Thorax 2002; 57: 110-114.

67. Nielsen NH, Bronfort G, Bendix T et al. Chronic asthma and chiropractic spinal manipulation: a randomized controlled trial. Clin Exp Allergy 1995; 25: 80-88.

68. Singh V, Wisniewski A, Britton J, Tattersfield A. Effect of yoga breathing exercises (pranayama) on airway reactivity in subjects with asthma. Lancet 1990; 335: 1381-1383.

69. Ernst E. Breathing techniques - adjunctive treatment modalities for asthma? A systematic review. Eur Respir J 2000; 15: 969-72.

70. Hondras MA, Linde K, Jones AP. Manual therapy for asthma. Cochrane Database Syst Rev 2001; 1: CD001002.

71. Huntley A, White AR, Ernst E Relaxation therapies for asthma: a systematic review. Thorax 2002; 57: 127-31.

72. Hackman RM, Sterns JS, Gershwin ME. Hypnosis and asthma: a critical review. J Asthma 2000; 37: 1-15

73. Gift AG, Moore T, Soeken K. Relaxation to reduce dyspnea and axiety in COPD patients. Nurs Res 1992; 41: 242-246.

74. Thornby MA, Haas F, Axen K. Effect of distractive auditory stimuli on exercise tolerance in patients with COPD. Chest 1995; 107: 1213-1217.

75. McBride S, Graydon J, Sidani S, Hall L. The therapeutic use of music for dyspnea and anxiety in patients with COPD who live at home. J Holist Nurs 1999; 17: 229250.

76. Behera D. Yoga therapy in chronic bronchitis. $J$ Assoc Psysicians India 1998; 46: 207.

77. Niggemann B, Grüber C. Unproven diagnostic procedures in IgE-mediated allergic diseases. Allergy 2004; 59: 806-8.

78. Ali M. Correlation of IgE antibodies with specificity for pollen and mould allergy changes in electrodermal skin responses following exposure to allergens. Am J Clin Pathol 1989; 91: 357-359.

79. Krop J, Swiesczeck J, Wood A. Comparison of ecological testing with the Vegatest method in identifying sensitivities to chemicals, foods and inhalants. Am J Acupunct 1985; 13: 253-259.

80. Lewith GT, Kenyon JN, Broomfield J et al. Is electrodermal testing as effective as skin prick tests for diagnosing allergies? A double blind, randomized block desig study. BMJ 2001; 322: 131-134.

81. Semizzi M, Senna G, Crivellaro M et al. A doubleblind, placebo-controlled study on the diagnostic accuracy of an electrodermal test in allergic subjects. Clin Exp Allergy 2002; 32: 928-32.

82. Terr AI. The cytotoxic test. West J Med 1983; 139: 702703.

83. Benson TE, Arkins JA. Cytotoxic test for food allergy: evaluation of reproducibility and correlation. J Allergy Clin Immunol 1976; 58: 471-476.

84. Lehman CW. The leukocytic food allergy test: a study of its reliability and reproducibility. Effect on diet and sublingual drops on the test. Ann Allergy 1980; 45: 150-158.

85. Liberman P, Crawford L, Bjelland J et al. Controlled study of the cytotoxic food test. JAMA 1975; 231: 728730 .

86. Garrow JS. Kinesiology and food allergy. $\mathrm{Br}$ Med J 1998; 296: 1573-1574.

87. Ludtke R, Kunz B, Seeber N, Ring J. Test retest reliability and validity of the kinesiology muscle test. Complement Ther 2001; 9: 141-145.

88. Jewett DL, Fein G, Greenberg MH. A double-blind study of symptom provocation to determine food sensitivity. N Engl J Med 1990; 323: 429-33.

89. Fox RA, Sabo BM, Williams TP, Joffres MR. Intradermal testing for food and chemical sensitivities: a double-blind controlled study. J Allergy Clin Immunol 1999; 103: 907-11.

90. Teuber SS, Vogt PJ. An umproven technique with potentially fatal outcome: provocation neutralization in a patient with systemic mastocytosis. Ann Allergy Asthma Immunol 1999; 82: 62-65.

91. Sethi TJ, Lessof MH, Kemeney DM et al. How reliable are commercial allergy tests? Lancet 1987; 101: 92-94.

92. Ernst E. Iridology: not useful and potentially harmful. Arch Ophtalmol 2000; 118: 120-121.

93. Teuber SS, Porch-Curren C. Unproved diagnostic and therapeutic approaches to food allergy and intolerance. Curr Opin Allergy Clin Immunol 2003; 3: 217-21.

94. Senna GE, Passalacqua G, Lombardi C, Antonicelli L. Position paper: controversial and unproven diagnostic procedures for food allergy. Allerg Immunol (Paris) 2004; 36: 139-45.

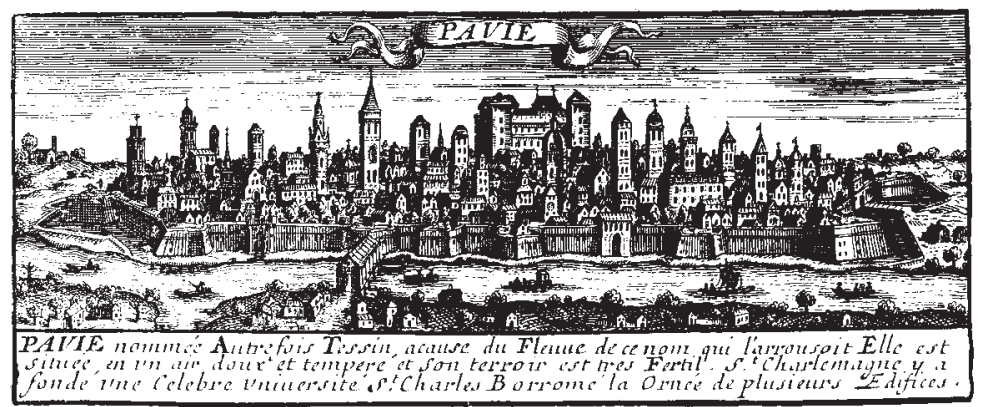

